\title{
COMPENSATORY AND SUSCEPTIVE RESPONSES OF COWPEA GENOTYPES TO INFESTATION BY APHIS CRACCIVORA KOCH.
}

\author{
F. Kusi ${ }^{1}$, D. Obeng-Ofori ${ }^{2}$, S. K. Asante ${ }^{1}$, F. K. Padi ${ }^{3}$ \\ ${ }^{1}$ CSIR-Savanna Agricultural Research Institute, P.O. Box TL 52, Tamale, Ghana. \\ ${ }^{2}$ Department of Crop Science, School of Agriculture, College of Agriculture and Consumer \\ Sciences, University of Ghana, P.O. Box LG 44, Legon, Ghana. \\ ${ }^{3}$ Cocoa Research Institute of Ghana, P.O. Box 8, New Tafo, Akim, Ghana.
}

\begin{abstract}
The aim of the study was to estimate yield loss to10 selected genotypes of cowpea as a result of Aphis craccivora infestation during the vegetative phase of the crop. There were two trials with four replications. The first trial serving as the control was sprayed at the seedling, flowering and podding stages against insect pests with lambda cyhalothrin $\left(P A W A^{\circledR}\right)$. The other trial was sprayed only at flowering and podding stages. The cowpea seedlings of the second trial were infested with five four-day-old aphids per seedling two weeks after planting. The aphids were allowed to form colonies and fed on the seedlings until symptoms of damage were observed. When the susceptible seedlings became stunted with distorted leaves and yellowing of leaves at two weeks after infestation (28 days after planting), aphids were controlled. The results showed that aphids' infestation delayed flowering and maturity of genotypes of cowpea. With the exception of early flowering genotypes all the medium to late flowering genotypes produced higher dry grain yield in infested plots than the control plots. The trend was not different from the production of dry biomass. The results of the present study implies that control of aphids infestation in early maturing cowpea genotypes should not be delayed up to two weeks after infestation or 28 days after planting. Aphid's infestation period for studies in susceptive response in medium to late maturing genotypes should go beyond 28 days after planting probably up to 35 days after planting.
\end{abstract}

Keywords: Cowpea, Aphis craccivora, Compensatory, Susceptive

\section{INTRODUCTION}

The amount of useful product that is obtained from crop plants or livestock is commonly referred to as 'yield'. Estimates of yield may be quantitative or qualitative which will vary for a given crop or livestock system according to weather, the levels and types of input and pest incidence (Dent, 1991). However, since conditions are rarely optimal, actual yields are nor- mally well below those that are theoretically obtainable. Yield loss assessments attempt to account for the difference between actual and attainable yield.

The intensity of pest attack can be described as the product of three effects: the numbers of the pest present, their development stage and the duration of the pest attack. It is the combination 


\section{Kusi et al.}

of these three factors in relation to the crop that influences crop yield (Dent, 1991). The presence of sucking insects acts as a sink for the phloem, redirecting a large part of it away from the tissue for which it was intended and into the insect gut. In this way, an infestation of phloem feeding insects may interfere with the normal partition of photosynthates between plant organs (Bardner and Fletcher, 1974). Aphis craccivora Koch (Homoptera: Aphididae) is phloem feeding insect, and a major insect pest of cowpea in Africa, Asia, and the Americas (Obeng-Ofori, 2007). The pest primarily infests the seedlings of cowpea and causes direct damage on the crop by sucking plant sap, resulting in stunted plants and distorted leaves and indirect damage by transmitting aphid-borne cowpea mosaic viruses (Bock and Conti, 1974). Singh and Allen (1980) estimated yield losses of $20 \%$ to $40 \%$ in cowpea due to A. craccivora infestation in Asia and up to $35 \%$ in Africa. The aim of the present study therefore, was to estimate yield loss to 10 genotypes of cowpea as a result of $A$. craccivora infestation.

\section{MATERIALS AND METHODS}

Genotypes used in the study

Ten genotypes used for the study consisted of four advanced breeding lines $\left(\mathrm{F}_{6}\right)$ developed from IT $\times$ P148 - 2 (Apagbaala) $\times$ UCR 01-1152 and one from UCR 01-15-127-2 $\times$ Sul 515 2 (Marfo-Tuya). The adapted parents (Apagbaala and Marfo-Tuya), and three varieties developed by the International Institute of Tropical Agriculture (IITA), Ibadan, Nigeria, namely, IT97K-499-35, IT95K-193-2 and IT98K-506-1 were used as controls(Table 1).

\section{Experimental procedure}

Yield loss assessment of the 10 selected genotypes was carried out in the screen house of Savanna Agricultural Research Institute (SARI). The genotypes were planted in plastic pots (measuring $28 \mathrm{~cm}$ deep and $28 \mathrm{~cm}$ wide) filled with heat sterilized sandy loamy soil. The treatments were replicated four times in a completely randomized design. Three seeds were sown per pot and the seedlings were thinned to one plant at seven days after emergence. There were two trials, one trial serving as a check was sprayed on three occasions (seedling, flowering and podding stages) against insect pests with a synthetic pyrethroid, lambda cyhalothrin $\left(\mathrm{PAWA}^{\circledR}\right.$ ), at the rate of 20 $\mathrm{g}$ active ingredient $\mathrm{ha}^{-1}$, whilst the other trial was sprayed only on two occasions (flowering

Table 1. Description of the 10 genotypes of cowpea by parentage or source

\begin{tabular}{ll}
\hline Genotype & Description \\
\hline APAGBAALA & $\begin{array}{l}\text { Prima/TVu } \quad \text { 4552/California Blackeye } \\
\text { No.5//7977. Cultivar, released in 2002 in Ghana }\end{array}$ \\
IT 97K-499-35 & $\begin{array}{l}\text { Breeding line from the IITA, Ibadan, Nigeria } \\
\text { IT 98K-506-1 }\end{array}$ \\
IT 95K-193-2 & Breeding line from the IITA, Ibadan, Nigeria \\
MARFO-TUYA & $\begin{array}{l}\text { Sumbrisogla/518-2. Cultivar, released in 2002 in } \\
\text { Ghana. 518-2 is of exotic background }\end{array}$ \\
SARC 1-34-2 & Apagbaala/ UCR 01-11-52 \\
SARC 1-57-2 & Apagbaala/ UCR 01-11-52 \\
SARC 1-91-1 & Apagbaala/ UCR 01-11-52 \\
SARC 3-74A-2 & Apagbaala/ UCR 01-11-52 \\
\hline
\end{tabular}


and podding stages). The cowpea seedlings of the second trial were infested with five fourday-old aphids per seedling two weeks after planting (Annan et al., 1995; Bosque-Perez and Schotzko, 2000). The A. craccivora used for the infestation were culture in insectary on Apagbaala, a susceptible host. The aphids were allowed to form colonies and fed on the seedlings for a period of two weeks, when the susceptible genotypes started showing symptoms of damage. When the susceptible seedlings became stunted with distorted leaves and more or less yellowing of leaves at two weeks after infestation (i.e. 28 days after planting), the aphids were controlled with lambda cyhalothrin $\left(\right.$ PAWA $\left.^{\circledR}\right)$. At plant maturity (60-70 days after planting), the pods were harvested, dried, hand threshed and the grain weight was recorded using electronic balance (Stanton 461AN).

Percentage grain yield reduction due to aphid infestation was calculated as:

Yieldin uninfesteфlot- Yieldin infestedplot Yieldin uninfesteфlot

The following agronomic data were also recorded: days to $50 \%$ flowering, days to maturity and weight of biomass at maturity.

\section{Measurement of weather variables}

Temperature and relative humidity monitored throughout the period of experiment using Thermohygrometer (Casella) were as follows, the average temperature in the insectary during this study fluctuated between $24.5{ }^{\circ} \mathrm{C} \pm 0.5$ and $37.5{ }^{\circ} \mathrm{C} \pm 1$ (Mean: $31{ }^{0} \mathrm{C}$ ) whilst the average relative humidity also fluctuated between $48.8 \% \pm 2$ and $90 \% \pm 1$ (Mean: 69.4).

\section{Statistical analysis}

Genstat statistical software ( ${ }^{\text {rd }}$ edition) was used to analyze the data. Fisher's LSD was used to separate the means after ANOVA showed significant differences. T-Test was also used to test the null hypothesis that mean dry grain and biomass yield of plants in the noinfestation plots were equal to mean dry grain and biomass yield of infested plots.

\section{RESULTS}

\section{Days to Flowering and Maturity}

Days to flowering differed significantly among the genotypes when they were not infested $(\mathrm{F}=$ 83.57; $\mathrm{DF}=9,27 ; \mathrm{P}<0.001)$ or infested $(\mathrm{F}=$ 45.36; $\mathrm{DF}=9,27 ; \mathrm{P}<0.001)$ (Table 2). Under condition of no infestation, SARC 1-57-2 and SARC 1-71-2 significantly $(\mathrm{P}<0.001)$ flowered earlier than the rest of the genotypes (36.25 and 40.25 days, respectively). SARC 157-2 also significantly flowered earlier than SARC 1-71-2. Significantly (P < 0.001), SARC 3-74-2 took more days to flower after planting (50 days). The rest of the genotypes were considered as medium cultivars in terms of days to flowering (45 - 47.75 days). Similarly, under aphid infestation, SARC 1-57-2 flowered significantly earlier (42.75 days) than the other genotypes $(\mathrm{P}<0.001)$. Apagbaala took more days (56.50) to flower after planting whilst the rest of the genotypes flowered between 46.25 and 53.00 days after planting.

Similarly, significant differences were observed among the genotypes under both no infestation $(\mathrm{F}=70.07 ; \mathrm{DF}=9,27 ; \mathrm{P}<0.001)$ and infestation $(\mathrm{F}=149.95 ; \mathrm{DF}=9,27 ; \mathrm{P}<0.001)$ conditions with regard to days to maturity (Table 2). Like the days to flowering, SARC 1-57-2 and SARC 1-71-2 significantly ( $\mathrm{P}<0.001)$ matured earlier (52 and 55.25 days, respectively) than the rest of the genotypes under no infestation with SARC 1-57-2 being earlier than SARC 171-2. The late to mature genotype was SARC 3 -74-2 which took 65.25 days to mature. The medium maturing genotypes were Apagbaala, IT97K-499-35, IT 98K- 506-1, IT95K-193-2, Marfo-Tuya, SARC 1-34-2 and SARC 1-91-1 which matured between 60 and 62 days after planting. On cowpea infested with aphids, SARC 1-57-2 matured earlier (55.50 days) than the rest followed by SARC 1-71-2 and MarfoTuya (60.75 and 61.75 days, respectively).

Apagbaala matured late among the genotypes with 71.25 days. Under both conditions of in- 


\section{Kusi et al.}

Table 2. Mean days to flowering $( \pm \mathrm{SE})$ and maturity $( \pm \mathrm{SE})$ of cowpea genotypes for no infestation and aphid-infested plots ${ }^{1}$

\begin{tabular}{lllll}
\hline Genotype & Days to Flowering & & \multicolumn{2}{l}{ Days to Maturity } \\
& No infestation & Infestation & No infestation & Infestation \\
\hline SARC 3-74-2 & $50.0 \pm 0.25$ & $52.5 \pm 0.50$ & $65.3 \pm 0.41$ & $67.3 \pm 0.48$ \\
IT97K-499-35 & $47.8 \pm 0.25$ & $53.0 \pm 0.41$ & $62.5 \pm 0.29$ & $68.8 \pm 0.25$ \\
Apagbaala & $47.3 \pm 0.47$ & $56.5 \pm 0.63$ & $62.0 \pm 0.48$ & $71.3 \pm 0.25$ \\
SARC 1-34-2 & $47.0 \pm 0.47$ & $49.0 \pm 0.85$ & $62.8 \pm 0.48$ & $64.5 \pm 0.25$ \\
IT95K-193-2 & $46.8 \pm 0.41$ & $48.3 \pm 0.25$ & $61.3 \pm 0.25$ & $64.8 \pm 0.25$ \\
IT 98K- 506-1 & $45.5 \pm 0.43$ & $52.3 \pm 0.41$ & $60.8 \pm 0.48$ & $66.8 \pm 0.29$ \\
SARC 1-91-1 & $45.5 \pm 0.43$ & $49.0 \pm 0.47$ & $60.0 \pm 0.58$ & $65.5 \pm 0.29$ \\
Marfo-Tuya & $45.0 \pm 0.63$ & $47.3 \pm 0.29$ & $60.3 \pm 0.47$ & $61.8 \pm 0.48$ \\
SARC 1-71-2 & $40.3 \pm 0.29$ & $46.5 \pm 0.91$ & $55.3 \pm 0.47$ & $60.8 \pm 0.50$ \\
SARC 1-57-2 & $36.8 \pm 0.41$ & $42.8 \pm 0.65$ & $52.0 \pm 0.48$ & $55.5 \pm 0.47$ \\
Mean & 45.25 & 49.70 & 60.20 & 64.67 \\
S.E.D & 0.602 & 0.826 & 0.651 & 0.516 \\
CV (\%) & 1.9 & 2.3 & 1.5 & 1.1 \\
\hline
\end{tabular}

${ }^{1}$ Values represent means of 4 replications.

festation with aphids, SARC 1-57-2 and SARC 1-71-2 were the early maturing genotypes.

Grain yield and dry biomass per hectare

Grain yield differed significantly among the genotypes under conditions of no infestation ( $\mathrm{F}$ $=7.32 ; \mathrm{DF}=9,27 ; \mathrm{P}<0.001)$ and infestation $(\mathrm{F}$ $=10.19 ; \mathrm{DF}=9,27 ; \mathrm{P}<0.001)$ (Table 3$)$. Under no infestation condition, IT97K-499-35 and Marfo-Tuya produced significantly $(\mathrm{P}<0.001$ ) high grain yield $\left(865 \mathrm{~kg} \mathrm{ha}^{-1}\right.$ and $729 \mathrm{~kg} \mathrm{ha}^{-1}$ respectively) followed by SARC1-71-2, SARC1-57-2 and SARC1-91-1. Apagbaala recorded significantly $(\mathrm{P}<0.001)$ the lowest dry grain yield of $365 \mathrm{~kg} \mathrm{ha}^{-1}$. The rest of the genotypes recorded dry grain yield between 542 and $417 \mathrm{~kg} \mathrm{ha}^{-1}$. Under aphid infestation, IT95K-193-2, IT97K-499-35 and Marfo-Tuya produced significantly $(\mathrm{P}<0.001)$ high dry grain yields $\left(896-823 \mathrm{~kg} \mathrm{ha}^{-1}\right)$. Apagbaala recorded the lowest dry grain yield of $427 \mathrm{~kg}$ $\mathrm{ha}^{-1}$.

The ANOVA for dry biomass yield indicated significant differences among genotypes both under infestation $(\mathrm{F}=11.53$; $\mathrm{DF}=9,27 ; \mathrm{P}<$ $0.001)$ and no infestation $(\mathrm{F}=20.41 ; \mathrm{DF}=9$, 27; $\mathrm{P}<0.001)$. Under no infestation, IT95K193-2 yielded significantly $(\mathrm{P}<0.001)$ higher dry biomass per hectare $\left(5558 \mathrm{~kg} \mathrm{ha}^{-1}\right)$ than the others. The genotype, SARC 1-57-2, recorded the lowest dry biomass yield $\left(2846 \mathrm{~kg} \mathrm{ha}^{-1}\right)$. Under aphid infestation, IT95K-193-2 recorded significantly $(\mathrm{P}<0.001)$ high biomass yield (6225) followed by SARC 3-74-2 $(5376 \mathrm{~kg}$ $\left.\mathrm{ha}^{-1}\right)$. SARC 1-57-2 recorded the lowest dry biomass yield (2599 $\mathrm{kg} \mathrm{ha}^{-1}$ ) whilst those of the rest appeared as medium.

The dry grain and biomass loss/gain due to 
Compensatory and Susceptive Responses of Cowpea Genotypes...

aphids' infestation (Table 4) was calculated from the mean dry grain and biomass yield per hectare. The results showed only SARC 1-57-2 and SARC 1-71-2 recording dry grain yield loss of $5.41 \%$ and $4.80 \%$, respectively. The other genotypes recorded gains in dry grain yield. Similarly, SARC 1-57-2 and SARC 1-712 were the only genotypes that recorded dry biomass yield loss due to aphids' infestation whilst the other genotypes recorded gain in dry biomass yield per hectare.

However, test of null hypothesis that mean grain yield of plants in the no-infestation plots were equal to mean grain yield of infested plots indicated no significant difference (Test statistic $\mathrm{t}=-1.11$ on $18 \mathrm{Df}$; Probability $=0.281$ ).

Similarly, test of null hypothesis that mean dry biomass yield of no-infestation was equal to mean dry biomass of infested plot showed no significant difference $($ Test statistic $\mathrm{t}=-0.78$ on 18 Df; Probability $=0.445$ ).

\section{DISCUSSION}

The results of the present study have shown that aphid infestation delayed flowering and maturity of cowpea genotypes. The study also indicated that, with the exception of the early flowering genotypes, the medium to late flowering genotypes produced higher dry grain yield in the infested plots than the non-infested plots. The trend was not different from the production of dry biomass; SARC 1-57-2 and SARC 1-71-2 were the only genotypes that produced higher biomass in the no infestation than the infested plots.

The type of damage caused by insects varies greatly, due to the confounding effects of the intensity of infestation, duration of attack and plant growth stage (Poston et al., 1983). Despite this, it is useful to identify general forms

Table 3. Mean Grain weight $( \pm$ SE) and Dry biomass $( \pm$ SE) of cowpea genotypes on no infestation and aphid infested plots ${ }^{1}$

\begin{tabular}{lllll}
\hline Genotype & \multicolumn{2}{l}{ Grain Weight (kg/ha) } & \multicolumn{2}{l}{ Dry Biomass (kg/ha) } \\
& No infestation & Infestation & No infestation & Infestation \\
\hline IT97K-499-35 & $865 \pm 62.21$ & $875 \pm 62.21$ & $4509 \pm 137.76$ & $4706 \pm 113.96$ \\
Marfo-Tuya & $729 \pm 39.44$ & $823 \pm 45.00$ & $4267 \pm 144.71$ & $4463 \pm 284.53$ \\
SARC 1-71-2 & $667 \pm 19.95$ & $635 \pm 38.04$ & $4207 \pm 79.33$ & $3726 \pm 112.30$ \\
SARC 1-57-2 & $573 \pm 46.19$ & $542 \pm 43.37$ & $2846 \pm 133.67$ & $2599 \pm 418.27$ \\
SARC 1-91-1 & $573 \pm 77.02$ & $677 \pm 78.64$ & $3963 \pm 99.25$ & $4204 \pm 295.49$ \\
IT 98K- 506-1 & $469 \pm 34.02$ & $542 \pm 34.02$ & $4568 \pm 36.36$ & $5265 \pm 143.55$ \\
IT95K-193-2 & $490 \pm 59.84$ & $896 \pm 88.39$ & $5558 \pm 360.76$ & $6225 \pm 270.19$ \\
SARC 3-74-2 & $469 \pm 38.04$ & $510 \pm 19.95$ & $4871 \pm 54.35$ & $5376 \pm 410.82$ \\
SARC 1-34-2 & $417 \pm 80.46$ & $500 \pm 54.79$ & $4362 \pm 116.81$ & $5195 \pm 404.82$ \\
Apagbaala & $365 \pm 80.48$ & $427 \pm 35.58$ & $4327 \pm 34.84$ & $4686 \pm 59.91$ \\
Mean & 569 & 635.4 & 4347.8 & 4644.5 \\
S.E.D & 80.5 & 74.6 & 215.0 & 416.1 \\
CV (\%) & 20.3 & 16.5 & 7.0 & 12.7 \\
\hline Values represent & & &
\end{tabular}

${ }^{\mathrm{T}}$ Values represent means of 4 replications. 


\section{Kusi et al.}

Table 4. Percentage dry grain and biomass loss/gain $(\mathrm{kg})$ per ha due to aphid infestation

\begin{tabular}{lcc}
\hline Genotype & \% Dry Grain Loss/Gain & \% Dry Biomass Loss/Gain \\
\hline IT97K-499-35 & $(1.15)^{1}$ & $(4.37)$ \\
Marfo-Tuya & $(12.9)$ & $(4.60)$ \\
SARC 1-71-2 & 4.80 & 11.43 \\
SARC 1-57-2 & 5.41 & 8.68 \\
SARC 1-91-1 & $(18.15)$ & $(6.08)$ \\
IT 98K- 506-1 & $(13.47)$ & $(15.26)$ \\
IT95K-193-2 & $(82.86)$ & $(12.00)$ \\
SARC 3-74-2 & $(8.74)$ & $(10.37)$ \\
SARC 1-34-2 & $(9.90)$ & $(19.10)$ \\
Apagbaala & $(16.99)$ & $(8.30)$ \\
\hline
\end{tabular}

${ }^{1}$ Values in brackets represent percentage gain in dry grain or biomass

of the relationships between yield and damage caused by insects. These relationships are categorized as: susceptive, tolerant or overcompensatory (Poston et al., 1983). The higher dry grain and biomass yield produced by Apagbaala, IT 98K- 506-1, IT95K-193-2, IT97K499-35, Marfo-Tuya, SARC 1-34-2, SARC 191-1 and SARC 3-74-2 in infested plots than the non-infested plots could be attributed to tolerant or over-compensatory depending on the margin of yield difference between the same genotype in infested and non-infested plots. The tolerant response is typical of insects feeding on the plant foliage or roots where a certain level of damage can be tolerated before yield is affected. Above the threshold level of damage, yield declines rapidly with increasing insect intensity, in much the same way as the susceptive response (Bardner and Fletcher, 1974; McNaughton, 1983). The overcompensatory response is where the plant initially reacts to damage in such a way that yield is actually increased above that which would have been achieved in the absence of the pest. This response is usually limited to early infestations and low levels of damage, so that damage greater than that causing over-compensation will reduce plant yield (Bardner and Fletcher,
1974; McNaughton, 1983).

The ability of a plant to compensate is influenced by several factors, including plant phenology, environmental conditions and the level of injury (Bardner and Fletcher, 1974; McNaughton, 1983). Aphids' damage to genotypes, 14 to 28 days after planting, could not induce susceptive response in the medium to late maturing genotypes. The only yield loss response was seen in the two early maturing genotypes, SARC 1-57-2 and SARC 1-71-2. This could also imply that the intensity of infestation, duration of attack and plant growth stage used in the present study was appropriate for early maturing genotypes. Hence, it can be recommended from this study that SARC 1-57-2, the resistant genotype (Kusi et al., 2008), should be evaluated with genotypes of the same maturity period using the same intensity of infestation, duration of attack and plant growth stage. The second important resistant genotype SARC 1-91-1(Kusi et al., 2008), could also be evaluated with the medium maturing genotypes, probably with a much longer duration of attack (up to 35 days after planting)

The results also showed that SARC 1-57-2 and 
SARC 1-91-1, the most resistant genotypes, recorded medium grain yield $\left(\mathrm{kg} \mathrm{ha}^{-1}\right)$ compared to the other genotypes. Although the most resistant genotypes did not perform poorly, the inability of the most resistant genotypes to produce high dry gain yield as in IT97K-499-35 and Marfo-Tuya under both infested and non-infested conditions could be attributed to yield penalty (Obeng-Ofori, 2007). Yield penalty is a problem associated with host -plant resistance, in that most mechanisms of plant resistance appear to involve some diversion of resources by the plant to extra structures for production of chemicals. Thus, it is by no means certain that any gene for resistance can be incorporated into high yielding varieties without some sacrifice in yield. Bottenberga et al., (1998) found that, compared with mixed cropping, host-plant resistance provided much greater control of insect populations and damage to cowpea pods and seeds. However, grain yield of the most resistant TVnu 72 genotype was significantly lower than that of the more susceptible cv 715 cowpea line indicating that TVnu 72 has a yield potential, which is significantly lower than that of cv 715 .

\section{CONCLUSION}

The results of the present study have shown that aphids' infestation delayed flowering and maturity of both early and medium to late maturing genotypes of cowpea. Control of aphid's infestation in early maturing cowpea genotypes should not be delayed up to two weeks after infestation (28 days after planting) to avoid yield loss. Aphid infestation period for studies in susceptive response in medium to late maturing genotypes should go beyond 28 days after planting probably up to 35 days after planting in order to assess yield loss due to aphids.

\section{ACKNOWLEDGEMENTS}

Financial support and facilities provided by the Challenge Programme on Water and Food (CPW\&F) project No. 6, Small Grant, Savanna Agricultural Research Institution (SARI) and Africa Regional Postgraduate Programme for Insect Science (ARPPIS) are gratefully ac- knowledged.

\section{REFERENCES}

Annan, I. B., Schaefers, G. A. and Tingey, W. M. (1995). Impact of density of Aphis craccivora Koch. (Aphididae) on growth and yield of susceptible and resistant cowpea cultivars. Annals of Applied Biology, 128(2):185-193.

Bardner, R. and Fletcher, K. E. (1974). Insect infestations and their effects on the growth and yield of field crops: a review. Bulletin of Entomological Research. 64:141-605.

Bock, K. R. and Conti, M. (1974). Cowpea aphid- born mosaic virus. Kew, UK, CMI (Commonwealth Mycological Institute). $\mathrm{CMI} / \mathrm{AAB}$ Description of plant viruses $134 \mathrm{pp}$.

Bosque-Perez, N. A. and Schotzko, D. J. (2000). Wheat genotype, early plant growth stage and infestation density effects on Russian wheat aphid (Homoptera: Aphididae) population increase and plant damage. Journal of Entomological Science. (35):22 - 38.

Bottenberga, H., Tamò, M. and Singh, B. B. (1998). Occurrence of phytophagous in sects on wild Vigna sp. and cultivated cowpea: comparing the relative importance of host-plant resistance and millet intercropping. Agriculture, Ecosystems and Environment (70):217 - 229.

Dent, D. 1991. Insect pest management. CAB international, Wallingford, UK, 604 pp.

Kusi, F., Obeng-Ofori, D., Asante, S. K., and Padi, F. K. (2008). New sources of resistance in cowpea to the cowpea a p h i d (Aphis craccivora Koch) (Homoptera: Aphididae). Plant-Arthropod interaction (submitted)

McNaughton, S.J. (1983). Compensatory plant growth as a response to herbivory. Oikos 0, pp. 329 - 336. 


\section{Kusi et al.}

Obeng-Ofori, D. (2007). Pests of grain legumes. In: Major pests of food and selected fruit and industrial crops in West Africa, D. Obeng-Ofori (ed.) The City publishers Ltd, Accra, pp. 81 - 112.

Poston, F. L., L. Pedigo, P. and Welch. S. M. (1983). Economic injury levels: reality and practicality. Bulletin on the Entomological Society of America 29, pp. 49 - 53. Singh, S. I. L. and Allen, D. J. (1980). Pests and diseases, resistance and protecttion in cowpea. In: Summerfield ILl (ed.) Advances in legumes Science, AH Bunting, $420 \mathrm{pp}$. 